\title{
COMPARISON OF INTRAVENOUS PARACETAMOL AND TRAMADOL AS PRE-EMPTIVE ANALGESIC FOR LOWER ABDOMINAL SURGERIES IN CHILDREN- A PROSPECTIVE RANDOMISED DOUBLE-BLIND STUDY
}

\author{
Seham Syeda1, Jyothi B2, Pratishruti Singh ${ }^{3}$, Safiya I. Shaikh ${ }^{4}$
}

${ }^{1}$ Senior Resident, Department of Anaesthesiology, NIMHANS, Bengaluru, Karnataka, India.

${ }^{2}$ Assocaite Professor, Department of Anaesthesiology, KIMS, Hubballi, Karnataka, India.

3 Postgraduate Student, Department of Anaesthesiology, KIMS, Hubballi, Karnataka, India.

4 Professor and HOD, Department of Anaesthesiology, KIMS, Hubballi, Karnataka, India.

\section{BACKGROUND}

ABSTRACT

Pre-emptive analgesia is administration of an analgesic before a painful stimulus, so as to prevent central sensitisation. Intravenous (IV) formulation of paracetamol has been introduced and its safety and pharmacokinetic properties have been established for children providing excellent analgesia and avoiding side effects associated with opioids and non- steroidal antiinflammatory drugs. Present study was done to compare the analgesic effects of pre-emptive I.V. paracetamol and tramadol in children undergoing lower abdominal surgeries.

\section{MATERIALS AND METHODS}

Sixty-four children of ASA physical status I and II, aged 2 to 12 years scheduled for elective lower abdominal surgeries under general anaesthesia were recruited for a prospective, randomized controlled, double blinded study, into group $\mathrm{P}$ and group $\mathrm{T}$. Following induction, group P received $15 \mathrm{mg} / \mathrm{kg}$ I.V. paracetamol and group T $1 \mathrm{mg} / \mathrm{kg}$ tramadol in $75 \mathrm{ml}$ of normal saline over 15 minutes before surgical stimulus. Postoperative modified objective pain scale (OPS), time to first rescue analgesia (FRA), Aldrete score, time to reach Aldrete score > 9, sedation scores, parent satisfaction scores and PONV were recorded for 24 hours.

\section{RESULTS}

Mean pain scores by OPS in group P and T were similar and statistically insignificant. Time to FRA being $320 \pm 20$ min in group P as compared to group T $340 \pm 30$ min. $12.5 \%$ patients had PONV in group P as compared to $81.5 \%$ in group T (p $\leq 0.05)$. Mean duration to reach Aldrete score of 9 was $11 \pm 1.5 \mathrm{~min}$ and $16.7 \pm 3 \mathrm{~min}$ in group $\mathrm{P}$ and $\mathrm{T}$ respectively $(\mathrm{p} \leq 0.05)$.

\section{CONCLUSION}

Pre-emptive I.V. paracetamol is as efficacious as I.V. tramadol for postoperative analgesia with early recovery and lower incidence of PONV in paracetamol group.

\section{KEYWORDS}

Paediatric, Postoperative Pain, Paracetamol, Tramadol.

HOW TO CITE THIS ARTICLE: Syeda S, Jyothi B, Singh P, et al. Comparison of intravenous paracetamol and tramadol as preemptive analgesic for lower abdominal surgeries in children- a prospective randomised double-blind study. J. Evolution Med. Dent. Sci. 2019;8(09):599-603, DOI: 10.14260/jemds/2019/133

\section{BACKGROUND}

Children can have most displeasing experience due to acute pain secondary to injury, illness or surgical intervention. ${ }^{1}$ Preemptive analgesia is regional or systemic analgesics administered prior to painful stimulus thereby preventing central sensitisation and subsequently reducing the analgesic requirement.2,3 The practice of multimodal analgesia is preferred for acute pain management in children with combination of drugs (NSAIDs, opioids, paracetamol etc.) and regional anaesthesia. Opioids provide satisfactory analgesia and better emergence, but prolonged sedation and other undesirable side effects such as post -operative nausea and

'Financial or Other Competing Interest': None.

Submission 15-06-2018, Peer Review 16-02-2019,

Acceptance 22-02-2019, Published 04-03-2019.

Corresponding Author:

Dr. Jyothi B,

Associate Professor,

Department of Anaesthesiology,

KIMS, Hubballi,

Karnataka, India

E-mail:dr.jyothib1@gmail.com

DOI: $10.14260 /$ jemds/2019/133 vomiting (PONV), respiratory depression, pruritus and urinary retention prolongs the recovery time and delayed discharge from the hospital 4 . NSAIDS are effective in reducing postoperative pain with a lower risk of PONV, however they introduce the possibility of increased bleeding due to its antiplatelet action. 5,6

Tramadol is a synthetic analogue of codeine which binds to opioid receptors and inhibits norepinephrine and serotonin uptake. Tramadol is efficacious in pain relief with its negligible effect on respiration when compared to traditional opioids. ${ }^{6}$ Paracetamol is a non-opioid analgesic which is devoid of risks associated with opioid and NSAIDS7. Its analgesic action is mediated by central inhibition of cyclooxygenase 2 (COX2), inhibition of nitric oxide generation via blockade of $\mathrm{N}$-methyl $\mathrm{D}$ aspartate receptors and activation of descending serotonergic pathways. Although, enteral formulations of paracetamol are the most commonly used, they are weak analgesic. Intravenous (I.V) paracetamol has been approved by FDA in 2011 for children more than 2 years of age. The target plasma concentration is achieved rapidly with reduced variability via intravenous compared to enteral route. 
A prospective randomized controlled, double blind study was conducted to evaluate the efficacy of pre-emptive I.V. paracetamol on postoperative analgesia and its effect on quality of recovery as compared to I.V. tramadol in children undergoing elective lower abdominal surgeries under general anaesthesia. The primary outcome of our study was to determine the duration of postoperative analgesia and the secondary outcome was to evaluate the quality of recovery, frequency of PONV and satisfaction scores among parents.

\section{MATERIALS AND METHODS}

A randomized controlled, double blind clinical study protocol was approved by institutional ethical committee. Based on previous article a minimum sample size of 26 in each group was obtained for detecting a difference of $8 \mathrm{~min}$ for time to FRA and population SD of 10 min with alpha of $5 \%$ and power of $80 \%$. A final total sample of 64 with 32 in each group was taken to avoid losses to follow-up. Written informed consent was obtained from patient's parents. Sixtyfour patients of American Society of Anaesthesiologists (ASA) I and II, aged between 2-12 years undergoing elective lower abdominal surgeries were included in the study protocol. Children who were allergic to the study drugs, those who had taken NSAIDS or any analgesic prior to 12 hours of surgery, acute renal and hepatic impairment were excluded from study. All children in the study were assessed by a preanesthetic evaluation a day prior to surgery and were fasted from solid food for 6 hours and clear fluids were permitted 2 hours prior to surgery.

Oral midazolam $0.5 \mathrm{mg} / \mathrm{kg}$ was given to children as a premedicant 30 minutes prior to surgery. Monitors like noninvasive blood pressure (NIBP), electrocardiography (ECG), pulse oximetry (SpO2) and end tidal carbon dioxide (ETCO2) monitors were connected. Children were pre-oxygenated with oxygen for 3 minutes. All children were induced by standard general anaesthesia with intravenous fentanyl 2 $\mu \mathrm{g} / \mathrm{kg}$, thiopentone sodium $5 \mathrm{mg} / \mathrm{kg}$ and $0.1 \mathrm{mg} / \mathrm{kg}$ vecuronium bromide. After endotracheal intubation, anaesthesia was maintained with $60 \%$ N20 in oxygen, sevoflurane to a MAC of 0.7 and intermittent boluses of vecuronium.

The study drug was then prepared by an anaesthesiologist who is not involved in anaesthetizing the patient. The medications were diluted with normal saline to a total volume of $75 \mathrm{ml}$. The anaesthesiologists who were administering the anaesthesia and assessing the parameters were blinded to the study drug being administered.

Randomisation and allocation were done by computer generated random number table through sequentially numbered, sealed, opaque envelopes which was opened just after induction of anaesthesia. Following induction and prior to skin incision, children were allocated to one of the two groups with 32 patients in each group. Patients in Group P (Paracetamol) received $15 \mathrm{mg} / \mathrm{kg}$ of I.V. paracetamol and group $\mathrm{T}$ (Tramadol) received $1 \mathrm{mg} / \mathrm{kg}$ of I.V. tramadol over 15 minutes (min).

Additional opioids were not administered intraoperatively. Intravenous fluid managed with ringer lactate solution, according to body weight fluid deficit and maintenance was calculated and replaced. At the end of the procedure neuromuscular blockade was reversed with I.V. neostigmine $0.05 \mathrm{mg} / \mathrm{kg}$ and glycopyrrolate $0.01 \mathrm{mg} / \mathrm{kg}$, and extubated when respiration was adequate and regular. Heart rate (HR), systolic blood pressure (SBP), diastolic blood pressure (DBP) and end tidal carbon-dioxide (ETCO2) were continuously monitored throughout the procedure.

Postoperative observational pain scores (OPS) described by Hannallah et al, ${ }^{8}$ Aldrete score, ${ }^{9}$ time to reach modified Aldrete score (MAS) of 10, HR and mean arterial blood pressure (MAP) were recorded for one hour in postanaesthetic care unit (PACU). Patients were then transferred to the ward. Postoperative pain was assessed using OPS at 2 , $46,8,10,12$ and 24 hours. This scale has been validated in infants and children between 2-13 years of age with scores ranging from 0 to 10.10

During first six hours OPS of 4 or more received rescue analgesic with I.V. meperidine $0.5 \mathrm{mg} / \mathrm{kg}$ and after 6 hours oral paracetamol $20 \mathrm{mg} / \mathrm{kg}$ was administered every 6 hourly. In the postoperative care unit hemodynamic parameters and scores were assessed by the same anaesthesiologist who was unaware of the patient group assignment. Adverse effects such as postoperative nausea and vomiting (PONV), sedation scores were recorded.

Nausea was defined as unpleasant feeling associated with intention to vomit and vomiting was defined as forceful ejection of gastric contents through mouth. Assessment of sedation was done by using a four-point scale where 0 - fully awake, 1 - awake but drowsy, 2 - sleeping but arousable by light touch or speech 3 - sleeping, not arousable. At the end of the study parents were asked to assess the quality of postoperative analgesia using parent satisfaction scores which were as follows: - 1 - bad, 2 - poor, 3 - good and 4 excellent.

All statistical analysis was performed using SPSS for Windows, version 11 (SPSS Chicago IC). Continuous data was summarized as Mean \& SD and analysed using $t$ test. Categorical data was summarized as frequency \&/or percentage and was analysed using Chi square or Fischer exact test. Kaplan Meir survival curves were constructed for time to discharge (time to achieve MAS of 10) for two groups and analysed using log rank test. P value less than 0.05 was considered significant for all statistical analysis.

\section{RESULTS}

Demographic data concerning patient's age, sex, weight, duration of surgery and anaesthesia and surgery were similar and comparable in the study groups (Table 1). Postoperative pain score by OPS at different time intervals (Graph 1 and Table 2) were statistically insignificant between two groups. Highest pain scores in both groups was noted at 6 hours postoperatively which decreased following administration of rescue analgesia. Time to first rescue analgesia (FRA) being $340 \pm 23.6$ min in group $P$ and $320 \pm 20.3$ in group $T$ which was significant ( $p=0.0006$, Table 3 ) Number of patients with MAS of 10 was $71.8 \%$ and $56.25 \%$ in group $\mathrm{P}$ and group $\mathrm{T}$ respectively, time taken to reach MAS of 10 as $11.03 \pm 1.18$ in group $\mathrm{P}$ and $16.72 \pm 3.37$ in group $\mathrm{T}$, with the difference between two being statistically significant $(p<0.05)$ as shown in table 4. Kaplan-Meier survival curves showed that Paracetamol group patients reached Aldrete score of 10 faster than patients in Tramadol group $(\mathrm{P}<0.001)$. Time to discharge was shorter with paracetamol. (Graph 2 and Table 5) Parent satisfaction scores weren't statistically different in both groups. 
Patients in group $\mathrm{T}$ had higher frequency of PONV when compared to group P (Table 6). Sedation scores was higher in group $\mathrm{T}$ when compared to group $\mathrm{P}$ with mean value being $0.80,0.56,0.41,0.41,0.19$ and 0.19 at $0,2,4,6,8,10,12$ and 24 hours respectively and statistically significant. (Table 7)

\begin{tabular}{|c|c|c|c|c|c|c|}
\hline \multirow[t]{2}{*}{ Variable } & \multirow[t]{2}{*}{ Group } & \multirow[t]{2}{*}{$\mathbf{n}$} & \multirow[t]{2}{*}{ Mean } & \multirow[t]{2}{*}{ SD } & \multicolumn{2}{|c|}{$\begin{array}{l}\text { Independent } \\
\text { t Test }\end{array}$} \\
\hline & & & & & t Value & p Value \\
\hline \multirow{2}{*}{$\begin{array}{c}\text { Age } \\
\text { (Years) }\end{array}$} & P Group & 32 & 8.09 & 2.48 & \multirow[t]{2}{*}{0.0482} & \multirow[t]{2}{*}{0.9617} \\
\hline & T Group & 32 & 8.06 & 2.70 & & \\
\hline \multirow{2}{*}{$\begin{array}{c}\text { Weight } \\
\text { (Kg) }\end{array}$} & P Group & 32 & 23.38 & 5.64 & \multirow[t]{2}{*}{1.205} & \multirow[t]{2}{*}{0.2327} \\
\hline & T Group & 32 & 21.69 & 5.56 & & \\
\hline \multirow{2}{*}{$\begin{array}{c}\text { Duration } \\
\text { of } \\
\text { Surgery } \\
\text { (Min) }\end{array}$} & P Group & 32 & 45.41 & 15.59 & \multirow[b]{2}{*}{0.315} & \multirow[b]{2}{*}{0.7533} \\
\hline & T Group & 32 & 44.16 & 16.08 & & \\
\hline \multicolumn{7}{|c|}{$\begin{array}{c}\text { Table 1. Distribution of Study Groups with Respect to Age, } \\
\text { Weight and Duration of Surgery }\end{array}$} \\
\hline
\end{tabular}

\begin{tabular}{|c|c|c|c|c|c|c|}
\hline \multirow{2}{*}{ Time } & \multirow{2}{*}{ Group } & \multirow{2}{*}{$\mathbf{N}$} & \multirow{2}{*}{ Mean } & \multirow{2}{*}{ SD } & \multicolumn{2}{|c|}{$\begin{array}{l}\text { Independent } \mathrm{t} \\
\text { test }\end{array}$} \\
\hline & & & & & t-value & $\begin{array}{c}\text { P- } \\
\text { value }\end{array}$ \\
\hline \multirow{2}{*}{0 hrs. } & P Group & 32 & 2.81 & 0.54 & \multirow{2}{*}{-0.825} & \multirow{2}{*}{0.412} \\
\hline & T Group & 32 & 2.94 & 0.67 & & \\
\hline \multirow{2}{*}{2 hrs. } & P Group & 32 & 2.38 & 0.49 & \multirow{2}{*}{-0.502} & \multirow{2}{*}{0.612} \\
\hline & T Group & 32 & 2.44 & 0.50 & & \\
\hline \multirow{2}{*}{4 hrs. } & P Group & 32 & 2.22 & 0.42 & \multirow{2}{*}{-0.569} & \multirow{2}{*}{0.570} \\
\hline & T Group & 32 & 2.28 & 0.46 & & \\
\hline \multirow{2}{*}{$6 \mathrm{hrs}}$. & P Group & 32 & 4.44 & 0.88 & \multirow{2}{*}{0.505} & \multirow{2}{*}{0.615} \\
\hline & T Group & 32 & 4.31 & 1.09 & & \\
\hline \multirow{2}{*}{8 hrs. } & P Group & 32 & 3.75 & 0.72 & \multirow{2}{*}{0.167} & \multirow{2}{*}{0.867} \\
\hline & T Group & 32 & 3.72 & 0.77 & & \\
\hline \multirow{2}{*}{10 hrs. } & P Group & 32 & 3.19 & 0.59 & \multirow{2}{*}{-1.002} & \multirow{2}{*}{0.320} \\
\hline & T Group & 32 & 3.34 & 0.65 & & \\
\hline \multirow{2}{*}{12 hrs. } & P Group & 32 & 2.06 & 0.25 & \multirow{2}{*}{0.000} & \multirow{2}{*}{1.000} \\
\hline & T Group & 32 & 2.06 & 0.25 & & \\
\hline \multirow{2}{*}{24 hrs. } & P Group & 32 & 2.03 & 0.18 & \multirow{2}{*}{0.000} & \multirow{2}{*}{1.000} \\
\hline & T Group & 32 & 2.03 & 0.18 & & \\
\hline \multicolumn{7}{|c|}{$\begin{array}{c}\text { Table 2. Comparison of Ops Between Group P and Group T } \\
\text { at Different Time Points }\end{array}$} \\
\hline
\end{tabular}

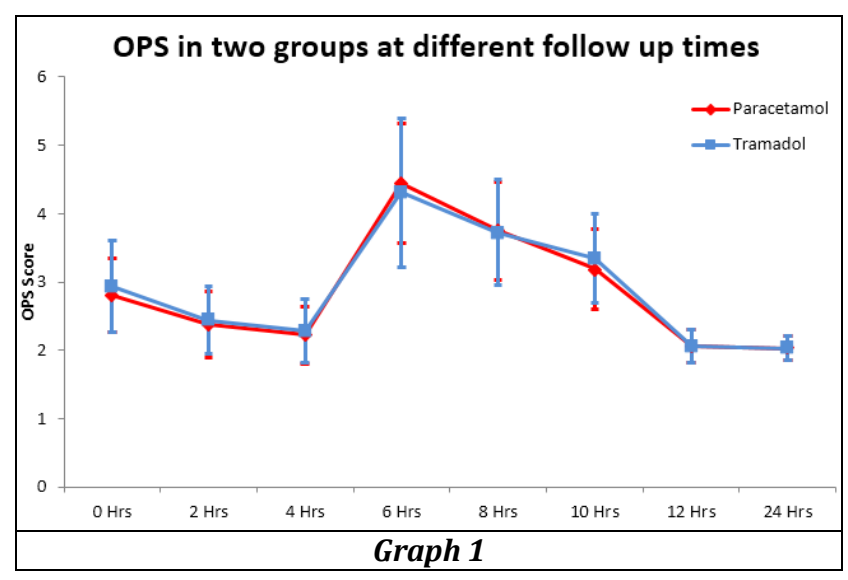

\begin{tabular}{|c|c|c|c|c|}
\hline \multirow{2}{*}{ Group } & \multirow{2}{*}{ Mean } & \multirow{2}{*}{ SD } & \multicolumn{2}{|c|}{ Independent t Test } \\
\cline { 4 - 5 } & & & t Value & p Value \\
\hline P group & 340 & 23.6 & 3.634 & $0.0006^{*}$ \\
\hline T group & 320 & 20.3 & & \\
\hline \multicolumn{3}{|c|}{ Table 3. Comparison Group of P and T with Respect to } \\
Time for First Rescue Analgesic in Min
\end{tabular}

\begin{tabular}{|c|c|c|c|c|}
\hline \multirow{2}{*}{ Group } & \multirow{2}{*}{ Mean } & \multirow{2}{*}{ SD } & Independent t Test \\
\cline { 1 - 3 } P group & 11.03 & 1.18 & 9.015 & $0.0001^{*}$ \\
\hline T group & 16.72 & 3.37 & & \\
\hline \multicolumn{3}{|c|}{ Table 4. Comparison of Group P and T with Respect to } \\
Time Taken to Reach MAS of 10 in Min \\
\hline \multicolumn{4}{|c|}{${ }^{\mathrm{p}<0.05}$} \\
\hline
\end{tabular}

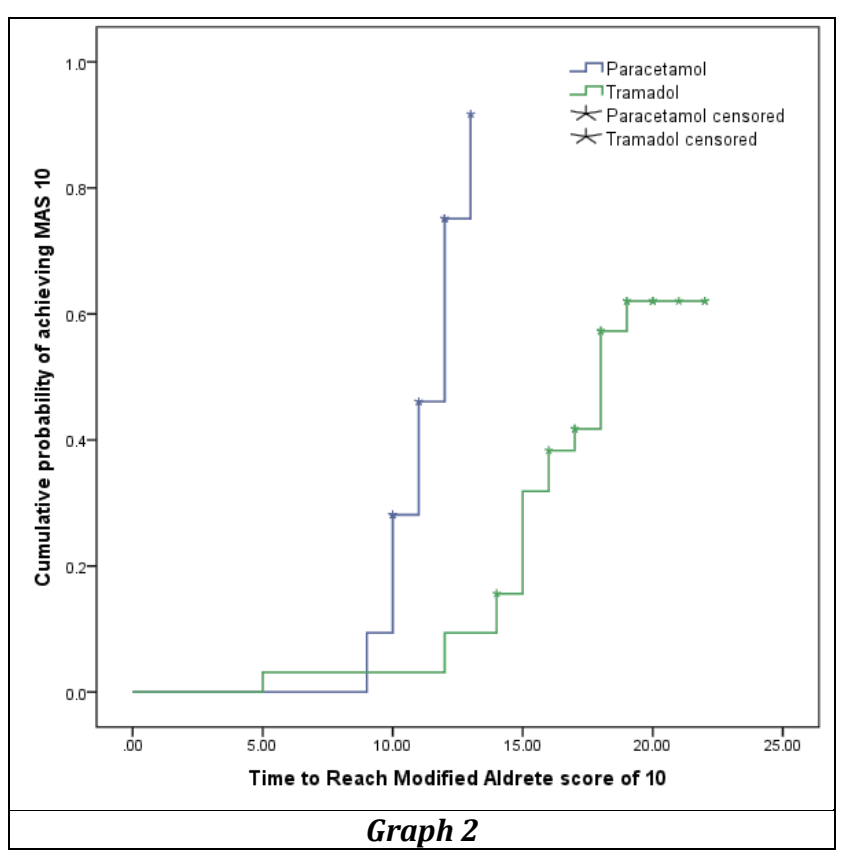

\begin{tabular}{|c|c|c|c|c|c|c|c|}
\hline & \multicolumn{3}{|c|}{ Mean } & \multicolumn{3}{|c|}{ Median } & \multirow{3}{*}{ 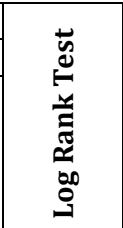 } \\
\hline & \multirow[b]{2}{*}{ 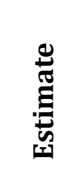 } & \multicolumn{2}{|c|}{$95 \% \mathrm{CI}$} & \multirow[b]{2}{*}{ 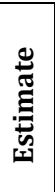 } & \multicolumn{2}{|c|}{$95 \%$ CI } & \\
\hline & & 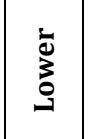 & 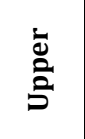 & & 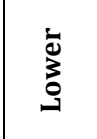 & 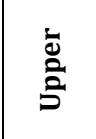 & \\
\hline Paraceta & 11.41 & 10.94 & 11.88 & 12 & 11.29 & 12.72 & \\
\hline Tramadol & 17.88 & 16.45 & 19.32 & 18 & 16.83 & 19.17 & $\mathrm{P}<0.001$ \\
\hline Overall & 15.34 & 14.13 & 16.55 & 15 & 13.13 & 16.87 & \\
\hline \multicolumn{8}{|c|}{ Table 5. Time to Reach Modified Aldrete Score of 10} \\
\hline
\end{tabular}

\begin{tabular}{|c|c|c|c|c|}
\hline Time & $\begin{array}{c}\text { P group } \\
(\mathbf{n = 3 2 )}\end{array}$ & $\begin{array}{c}\text { T group } \\
(\mathbf{n = 3 2 )}\end{array}$ & $\begin{array}{c}\text { Total } \\
(\mathbf{n = 6 4 )}\end{array}$ & $\begin{array}{c}\text { Fischer Exact } \\
\text { Test }\end{array}$ \\
\hline $0 \mathrm{hrs}$. & $0(0)$ & $26(81.25)$ & $26(40.63)$ & $\mathrm{P}<0.001^{*}$ \\
\hline $2 \mathrm{hrs}$. & $2(6.25)$ & $15(46.88)$ & $17(26.56)$ & $\mathrm{P}<0.001^{*}$ \\
\hline $4 \mathrm{hrs}$. & $2(6.25)$ & $13(40.63)$ & $15(23.44)$ & $\mathrm{P}=0.002^{*}$ \\
\hline $6 \mathrm{hrs}$. & $0(0)$ & $13(40.63)$ & $13(20.31)$ & $\mathrm{P}<0.001^{*}$ \\
\hline $8 \mathrm{hrs}$. & $0(0)$ & $13(40.63)$ & $13(20.31)$ & $\mathrm{P}<0.001^{*}$ \\
\hline $10 \mathrm{hrs}$. & $0(0)$ & $6(18.75)$ & $6(9.38)$ & $\mathrm{P}=0.024^{*}$ \\
\hline $12 \mathrm{hrs}$. & $0(0)$ & $6(18.75)$ & $6(9.38)$ & $\mathrm{P}=0.024^{*}$ \\
\hline $24 \mathrm{hrs}$. & $0(0)$ & $4(12.5)$ & $4(6.25)$ & $\mathrm{P}=0.113$ \\
\hline Table 6. Comparison of Group P and T with Respect to \\
PONV At Different Time Points \\
\hline \multicolumn{5}{|c|}{ *Significant } \\
\hline
\end{tabular}


[11] Uysal HY, Takmaz SA, Yaman F, et al. The efficacy of intravenous paracetamol versus tramadol for postoperative analgesia after adenotonsillectomy in children. J Clin Anesth 2011;23(1):53-7.

[12] Ewah BN, Robb PJ, Raw M. Postoperative pain, nausea and vomiting following paediatric day-case tonsillectomy. Anaesthesia 2006;61(2):116-22.

[13] Van den Berg AA, Halliday E, Lule EK, et al. The effects of tramadol on postoperative nausea, vomiting and headache after ENT surgery. A placebo controlled comparison with equipotent doses of nalbuphine and pethidine. Acta Anaesthesiol Scand 1999;43(1):28-33.
[14] Pang WW, Mok MS, Huang S, et al. Intraoperative loading attenuates nausea and vomiting of tramadol patient-controlled analgesia. Can J Anaesth 2000;47(10):968-73.

[15] Pendeville PE, Von Montigny S, Dort JP, et al. Double blind randomized study of tramadol vs. paracetamol in analgesia after day-case tonsillectomy in children. Eur J Anaesthesiology 2000;17(9):576-82.

[16] Alhashemi JA, Daghisthani MF. Effects of intraoperative I.V. acetaminophen vs i.m. meperidine on post-tonsillectomy pain in children. $\mathrm{Br} \mathrm{J}$ Anaesth 2006;96(6):790-5. 